\title{
Aspects regarding the reduction of fugitive methane emissions from the valves
}

\author{
Ioana Petre $^{1}$, and Monica Emanuela Stoica $^{2},{ }^{*}$ \\ ${ }^{1}$ Maverick Valves. Bv, The Netherlands \\ ${ }^{2}$ Petroleum-Gas University of Ploiesti, DPTH Department, 100560, Ploiesti, Romania
}

\begin{abstract}
Methane is the second strongest greenhouse gas contributing to climate change after carbon dioxide. Reducing methane emissions contributes to both slowing climate change and improving air quality. In order to reduce methane emissions from the energy sector, the European Commission has proposed the obligation to improve leak detection and disposal in fossil fuel infrastructure, as well as any other infrastructure that produces, transports or uses fossil fuels. Compressors and compressor stations are such a component of the energy system. The paper presents the testing procedures of the valves in the gas transmission pipes for the evaluation of external leaks and the proposed corrective actions to minimize them.
\end{abstract}

\section{Introduction}

The European Union, is committed to participating in the global effort to reduce greenhouse gas emissions, as a party to the Kyoto Protocol (1997) and the Paris Agreement (2015) [1]. The main component of natural gas is the methane.The potential type of gas that can effect greenhouse is (GHG). [2]. The methane is considerated the his level of heat capture power is higher than that of carbon dioxide.[3]

The European Commission considers that methane emissions from the energy field must be taken into account when achieving climate neutrality by 2050 . One of the EU targets to achieve until 2030 is the decarbonisation of methan reduction. It is estimated that current non- $\mathrm{CO}_{2}$ policies will lead to a $29 \%$ reduction of methane emissions in the EU until 2030. Methane will remain the main focus, greenhouse gas after $\mathrm{CO}_{2}$ in the EU. Forecasts indicate the need for progress in reducing methane emissions by $35 \%-37 \%$ by 2030 , compared to 2005.

There are methane leaks from fossil fuel production areas, transport systems, naval and distribution systems. When the carbon dioxide is released by flared combustion, there may be methane leaks during combustion. 54\% of methane emissions from the energy sector are fugitive emissions from petroleum industry [4]. In different countries, the gas emissions from petroleum industry are a source of GHG emissions [5].

\footnotetext{
* Corresponding author: monicastoica20022002@yahoo.com
} 
During the time the gas industry has received many criticism of air quality due to the operation and the production. The system consists of wells, gas collections and production facilities, transport in distribution pipelines. The cost-effective and impactful action that government can do to achieve the global climate goals is reducing methane emission from petroleum industry. The regulatory actions play an important role alongside voluntary actions in industry [6].

\section{Emissions}

\subsection{Types of emissions}

The release of emissions in air is done in different ways. Emissions are classified as follows: fugitive, combusted, and associated.

1. Fugitive emissions are considerate natural gas vapours that can be released to the atmosphere through the industry operations.

2. Combusted emissions are products that are obtained from the burning of natural gas during industry operations.

3. Associated emissions refer to secondary sources of emissions that arise from associated operations in natural gas systems. [7].

\subsection{Sources of Emissions}

In many industry activities and parts of equipment that have the potential to emit air pollutants are included in the natural gas systems. On the national construction and transportation, natural gas systems consist of kilometres of pipes [7]. Compressors and compression stations are some of the largest sources of gas emissions. Industrial valves are another component of gas emitters. Figure 1 shows the system of natural gas transportation.

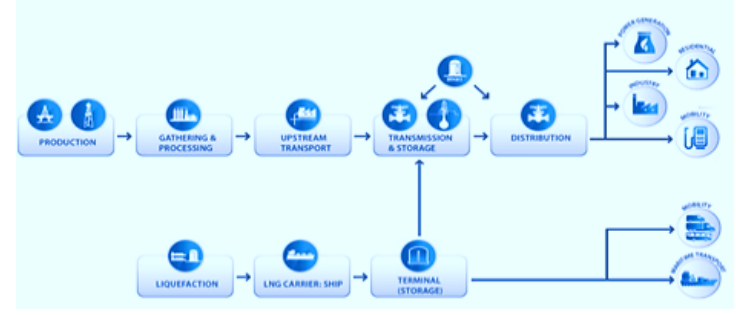

Fig. 1. The system of transportation of natural gas [8]

\section{Description of ball valve}

The valve balls are durable, well performant after many cycles, and reliable, closing securely even after long periods of disuse. The are considerated five type of body of ball valves are: single body, three-piece body, split body, top entry, and welded. [9].

The top entry body allows connection to the ball and seats for maintenance without having to disassembly the valve and it is preferred for larger sizes. In this case is not required to remove the valve from the pipe system. Generally the top entry ball valves are made from casting metal. The advantage of the top entry ball valves is its construction which allows minimal thread connection so that it will also minimize a possible leak. 
Side Entry Ball Valves are valves that assemble their ball from the side part. The body is usually made of a two piece or three piece. All the parts of the body is assembled by a bolt/stud. Side entry ball valves are usually made of forged metal. Construction of the body parts are forged and then assembled together. Base on the geometry the side entry ball valves are easy to assemble then the trim components are also easy to align. The design of the stem usually has rectangular portion of ball valve is not attached to the ball. [9]. Figure 2 shows a fugitive emissions test fixture.

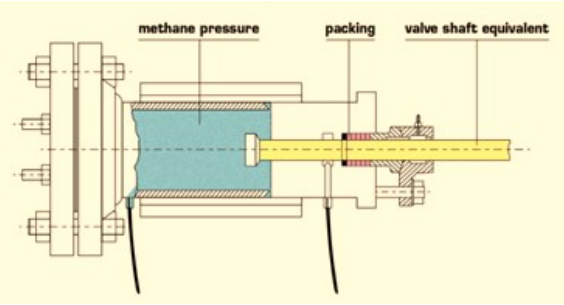

Fig. 2. Fugitive emissions test fixture [10]

The test procedures for the evaluation of external leaks of valve stems or shafts and joints of isolation valve bodies and control valves which are intended for application of volatile air pollutants and hazardous fluids are specified in ISO $15848[11,12,13]$ :

1 Fluid test: The test fluid must be helium gas with $97 \%$ minimum purity or methane.

2 Pressure testing: The pressure test must be 6 bar unless o agreed by the manufacturer and the buyer.

3 Test temperature: The test temperature must be at room temperature as defined in ISO 15848 .

4 Helium as test fluid: When the tested fluid is helium, the tightness classes are identified as $\mathrm{AH}$ classes, $\mathrm{BH}$ class and $\mathrm{CH}$ class. The measurement of the mass spectrometer with helium make connection to the speed at which a volume of helium at the specified pressure passes a given cross section of the test system. The response time of the helium mass spectrometer is evaluated (or verified) using the calibrated leakage standard and is recorded when the standard calibrated leakage is open to the helium mass spectrometer and when the output signal of the helium mass spectrometer becomes stable $[11,12,13]$. The principle of the local measurement sniffing illustrated in figure 3.
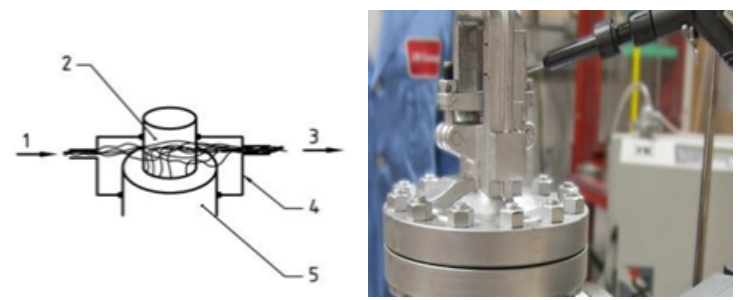

Fig. 3. Principle of the flush method for valve stem leak rate measurement

1 - flush gas, 2 - valve steam, 3 - to detector, 4 - flush chamber, 5 - valve body

The test valve is pressurized with Helium. The detector of the helium on a local place which escapes from the test valve. The sniffer probe is moved along the parts that are specified [14]. During fugitive emission testing

- Each fugitive testing emission shall be performed using the standard. 
- New product or design a new fugitive emission test must be performed.

- This means that if valve fails, the valve must be revised and tested again.

- Emission fugitive testing shall be performed by using the correct safety precautions.

Figure 4 shows the sealing area of packing graphite.
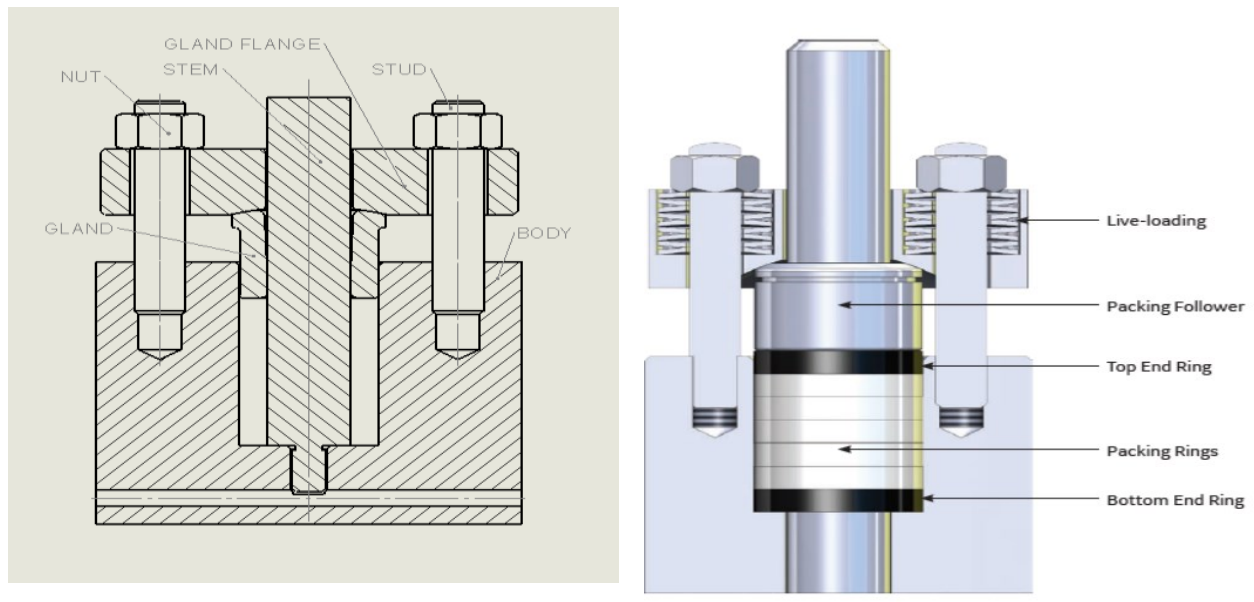

Fig. 4. Sealing area of packing graphite

The principle of the test detecting system of fugitive emission illustrated in figure 5 .

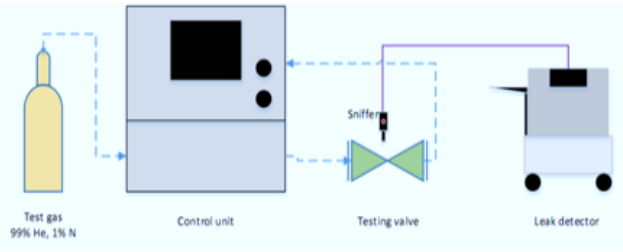

Fig. 5. The test detecting system of fugitive emission

The test evaluation report.

- Half open the test valve and pressurized to the level specified in 6 bar. Measure the stem seal leakage using the sniffing method in accordance with ISO 15848-1.

- Fully open and close the pressurized test valve 5 times.

- Half open the test valve after the mechanical cycles and measure the stem seal leakages as done.

In the ISO testing, helium is measured by capturing the test valve and measuring the quantity of helium leaking through the packing set. If the values of the required tightness are in the class according to Table 1, the test shall be considered as having failed [11]

Table 1.Tightness classes for steam (or shaft) base on the seals with methane [11, 12].

\begin{tabular}{|c|c|}
\hline Class & Measured leakage, ppmv \\
\hline AM & $\leq 50$ \\
\hline BM & $\leq 100$ \\
\hline CM & $\leq 500$ \\
\hline
\end{tabular}


The procedure for measuring the leakage of body seals is as follows: half open the test valve and pressurize to the level specified at 6 bar. After the test pressure has been balanced, leakage of the body seal(s) can be detected in accordance with ISO 15848-1:2015.

If the reading has positive values of the required tightness class according to Table 2 , the test shall be considered as having failed.

Table 2. Leakage from body seals $[11,12]$

\begin{tabular}{|c|c|}
\hline Measured leakage, ppmv & Measured leakage, $\mathrm{mbar} \cdot 1 / \mathrm{s}$ \\
\hline$\leq 50$ & $\leq 1 \times 10^{-4}$ \\
\hline
\end{tabular}

Test report shall be issued for all valves to be tested containing all relevant data. Failed or aborted tests shall also be reported with the actual results achieved up to the point of failure. Corrective actions on failed valves shall be reported as well.

As long as the valve does not relase to the atmosphere, an internal leak will not result in a fugitive emission. On opposite way, an external leak refers to a leak from inside the valve into the environment, for example, by way of the stem seal or body seal $[11,12]$.

\section{Case studies}

The study is present the test fugitive emission for ball valve size class 2 in class 300 and 3 in class 600 in accordance with ISO 15848-1-tightness class: A. Valve is pressurized to the specific level in 6 bar and measurement with leakage detector. When the ball rotate about an axis perpendicular to the flow is open when the ball's hole is in line with the flow and closed when it is pivoted 90 -degrees by the valve handle.

Test equipment and instrumentation: Calibrated pressure gauges of suitable scale; Gas leakage detector, Test gas mixture Nitrogen $90 \%+10 \% \mathrm{He}$.

On the first condition the stem is closed starting the procedure at 6 bar and measure with the sniffer at $3.91 \times 10-6 \mathrm{mbar} 1 / \mathrm{s}$. During the procedure had been noticed that at the 54 bar the sealing area of stem start to leakage with percentage of $3.6 \times 10-6 \mathrm{mbar} 1 / \mathrm{s}$. In accordance with the standard and criteria of acceptance the sealing area of the stem pass the test in condition of fully open condition of the ambient temperature of $50^{\circ} \mathrm{C}$. The test shall be considered having failed at $1 \times 10-4 \mathrm{mbar} 1 / \mathrm{s}$.
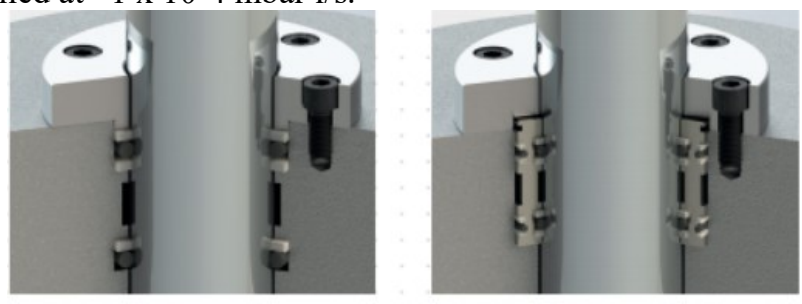

Fig 6. Stem sealing (Petro Valve -Side entry)

The sealing of the stem part is the packing in the valve, figure 6 , that is designed to prevent gas, liquid and other media leakage. Valve leakage will be caused by the deflection of gland fastening, improper packing bolt fastening, too little packing, wrong packing material and improper packing installation method in the installation process of packing. The second condition is pressurised test valve from fully opened to closed and the process is repeated 5 times. The acceptance criteria are the same as in the first case. The result during the test present that the valve can operate and function without having any kind of problem. The stem 
seal compression packing is energized the stem, the level of leakage $\left(3.6 \times 10^{-6} \mathrm{mbar} 1 / \mathrm{s}\right)$ don't created hazard to the environment.

In the case of the body seal leakage, the sealing area, figure 7 , starts to leak at $3.6 \times 10^{-6}$ mbar $1 / \mathrm{s}$. The level of the leakage is small compared with the standard criteria. Leaks can occur at end connections, body connections and between the bonnet cap and the body. In case of failure, the gasket surface may be damaged and the gasket needs to be replaced.
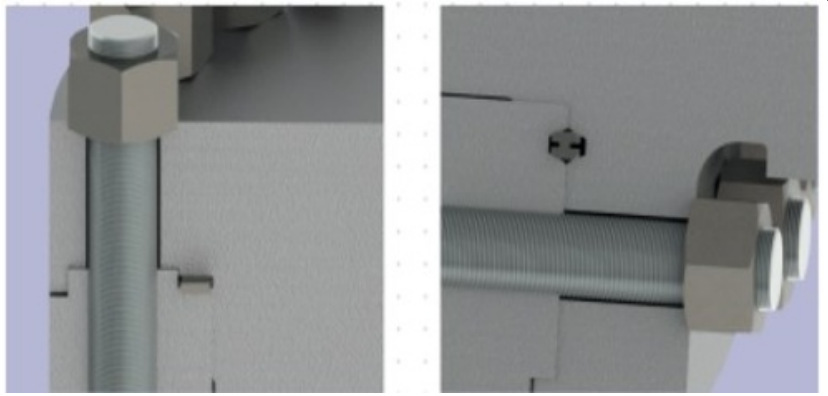

Fig. 7. Body sealing (PetroValve -Side entry)

The second case was taking in consideration a ball valve size 3 in class 600 (figure 8). The acceptance criteria of tightness was class A in accordance with ISO 15848-1. The valve is pressurized to the specific level of 6 bar and measurement is done with a leakage detector. According to the results of the test, the valve respects the criteria of acceptance for delivery in the transportation system.

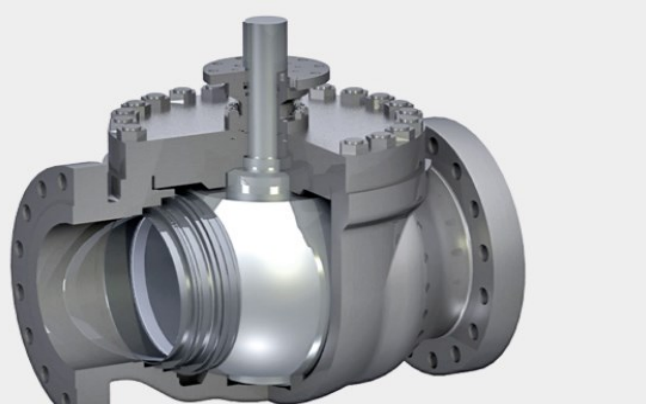

Fig. 8. Ball valve sealing (PetroValve -Side entry)

Table 3. Results obtained for the ball valve testing

\begin{tabular}{|c|c|c|c|c|c|}
\hline & \multicolumn{2}{|c|}{ Tests } & \multirow{2}{*}{$\begin{array}{c}\text { ACCEPTANCE } \\
\text { CRITERIA } \\
\text { (Tightness class A) } \\
6\end{array}$} & \multirow{2}{*}{\begin{tabular}{l}
\multicolumn{1}{c}{ TEST } \\
RESULTS \\
54
\end{tabular}} & \multirow{2}{*}{$\begin{array}{l}\text { COMMENTS } \\
\text { Stem } Ø 22 \mathrm{~mm}\end{array}$} \\
\hline $\begin{array}{l}\text { Ball valve } \\
\text { size class } 2\end{array}$ & \multirow{2}{*}{$\begin{array}{l}\text { stem } \\
\text { seal } \\
\text { leakage }\end{array}$} & $\begin{array}{l}\text { Pressure, } \\
\text { bar }\end{array}$ & & & \\
\hline $\begin{array}{l}\text { in class } \\
300\end{array}$ & & Leakage & $\begin{array}{l}\text { Stem: } \leq 3.91 \times 10^{-6} \\
\text { mbar } 1 / \mathrm{s}\end{array}$ & $\begin{array}{l}\text { Leakage: } 3.6 \\
\text { x } 10^{-6} \mathrm{mbar} \\
1 / \mathrm{s}\end{array}$ & $\begin{array}{l}\text { Test performed } \\
\text { at }-50^{*} \mathrm{C}\end{array}$ \\
\hline & \multirow{2}{*}{$\begin{array}{l}\text { body } \\
\text { seal } \\
\text { leakage }\end{array}$} & $\begin{array}{l}\text { Pressure, } \\
\text { bar }\end{array}$ & 6 & 54 & Sealing $\varnothing 34 \mathrm{~mm}$ \\
\hline & & Leakage & $\begin{array}{l}\text { Body/clos. : } \leq 6.02 \times \\
10^{-6} \mathrm{mbar} 1 / \mathrm{s}\end{array}$ & $\begin{array}{l}\text { Leakage: } 3.6 \\
\times 10^{-6} \mathrm{mbar} \\
1 / \mathrm{s}\end{array}$ & $\begin{array}{l}\text { Test performed } \\
\text { at }-50^{*} \mathrm{C}\end{array}$ \\
\hline
\end{tabular}




\begin{tabular}{|l|l|l|l|l|l|}
\hline $\begin{array}{l}\text { Ball valve } \\
\text { size } 3 \text { in } \\
\text { class } 600\end{array}$ & $\begin{array}{l}\text { stem } \\
\text { seal } \\
\text { leakage }\end{array}$ & $\begin{array}{l}\text { Pressure, } \\
\text { bar }\end{array}$ & 6 & 110 & Stem Ø27mm \\
\cline { 3 - 6 } & leakage & $\begin{array}{l}\text { Stem: } \leq 4.81 \times 10^{-6} \\
\text { mbar } 1 / \mathrm{s}\end{array}$ & $\begin{array}{l}\text { Leakage: } \\
4.80 \times 10^{-6} \\
\text { mbar } 1 / \mathrm{s}\end{array}$ & $\begin{array}{l}\text { Test performed } \\
\text { at }-50^{*} \mathrm{C}\end{array}$ \\
\cline { 2 - 6 } & $\begin{array}{l}\text { body } \\
\text { seal } \\
\text { leakage }\end{array}$ & Pressure,bar & 6 & 110 & Sealing Ø40mm \\
\cline { 3 - 6 } & leakage & $\begin{array}{l}\text { Body } / \mathrm{clos}: \leq 7.12 \times \\
10^{-6} \mathrm{mbar} 1 / \mathrm{s}\end{array}$ & $\begin{array}{l}\text { Leakage: } \\
3.81 \times 10^{-6} \\
\text { mbar } 1 / \mathrm{s}\end{array}$ & $\begin{array}{l}\text { Test performed } \\
\text { at }-50^{*} \mathrm{C}\end{array}$ \\
\hline
\end{tabular}

\section{Conclusion}

Industrial facilities control fugitive emission levels, it's essential that valve manufacturers and suppliers take extra measures to ensure their valves have secured stem-seals to prevent them from leaking hazardous gas or vapor into the environment.

- On of the effect on the sealing area between stem and gland could be corrosion effect in this case the valve manufacturers is taking in consideration prevent action of $3 \mathrm{~mm}$ more material.

- Other action prevent packing graphite that will not energiezed the stem and the sealing and could couse leaking on the enviroment. To evoit this problem on the offshore are measured and controled valve and are evaluted the lost by diagrams. In case of detecting the leaking the prodution is stop and is required from the supplier invetigation and instalation of another paking graphite.

\section{References}

1. http://www.eca.europa.eu/ [Accessed 13.03.2021]

2. http://unece.org [Accessed 12.02.2021]

3. C. Stafford, Energy\&Envtl.L.Rev, 26, 351 (2015)

4. https://op.europa.eu/en/ [Accessed 14.10.2020]

5. http://www.ipcc-nggip.iges.or.jp [Accessed 10.02.2021]

6. https://www.iea.org/reports/driving-down-methane-leaks-from-the-oil-and-gasindustry [Accessed 2.02.2021]

7. http://www. fas.org/sgp/crs/misc [Accesssed 9.02.2021]

8. http://www.aemc.gov.au [Accesssed 9.02.2021]

9. API 608/ISO 17292:2019, Metal ball valves-flanged, threaded, and welding ends (2019)

10. http://www.mrcglobal.com/Blog/Valves/Fugitive-Emissions [Accesssed 9.02.2021]

11. ISO 15848-1:2015 Industrial valves - Measurement, test and qualification procedures for fugitive emissions - Part 1: Classification system and qualification procedures for type testing of valves (2015)

12. ISO 15848-2:2015-Industrial valves - Measurement, test and qualification procedures for fugitive emissions - Part 2: Production acceptance test of valves

13. MESC SPE 77/312:2004 Fugitive emission production testing (2004)

14. API-600:2015 - Steel Gate Valves-Flanged and Butt-welding Ends, Bolted Bonnets (2015) 